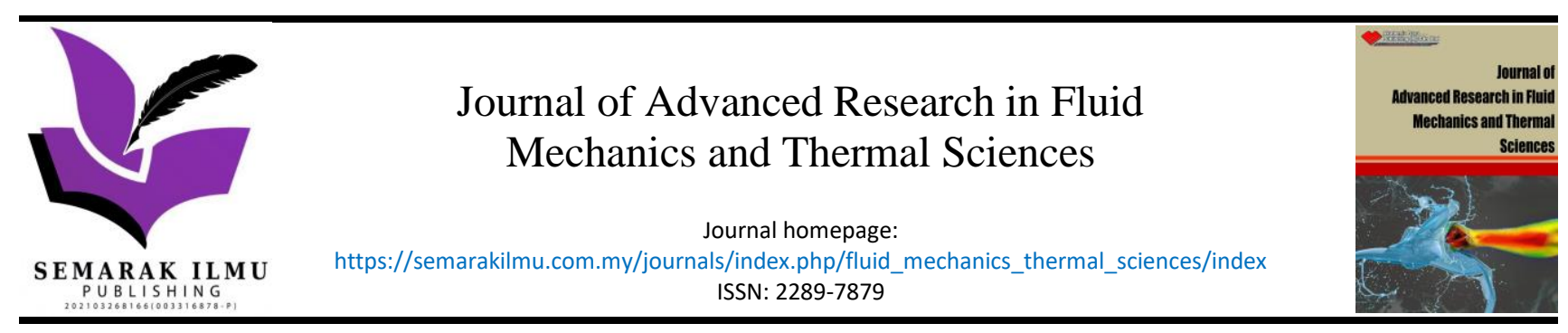

\title{
Design Intent of Future Tunnels
}

\author{
Mohammed Asadullah ${ }^{1,}{ }^{*}$, Sher Afghan Khan ${ }^{2}$, Parvathy Rajendran ${ }^{3,4, *}$, Ervin Sulaeman ${ }^{2}$ \\ Mechanical Engineering Department, Faculty of Engineering, Lords Institute of Engineering and Technology, Hyderabad, India \\ 2 Mechanical Engineering Department, Faculty of Engineering, International Islamic University Malaysia, Kuala Lumpur, Malaysia \\ 3 School of Aerospace Engineering, Universiti Sains Malaysia, Nibong Tebal, Penang, Malaysia \\ 4 Faculty of Engineering \& Computing, First City University College, Bandar Utama, 47800 Petaling Jaya, Selangor, Malaysia
}

ARTICLE INFO

\section{Article history:}

Received 14 August 2021

Received in revised form 26 September 2021

Accepted 28 September 2021

Available online 27 October 2021

Keywords:

High-speed Train; High-speed Tunnel;

Pressure Load; Mach Number

\section{ABSTRACT}

The sound barrier for bullet trains remains a challenge due to the piston effect causing compression waves at the entry and exit of the tunnel. The air ahead of the train nose is compressed, and the wave propagates through the tunnel at the speed of sound and exits with the generation of micro pressure waves. It gives rise to a complex wave pattern comprising compression at the train nose \& expansion at the train tail leading to the positive pressure around the nose and suction around the tail. This is intended to provide exhaustive input for the proper design of a futuristic tunnel. The crosssectional shapes of the tunnel, whether square, rectangular, circular, or semi-circular, will experience pressure compression wave generated by high-speed train but will influence the flow pattern and hence the compression wave. This paper presents the pressure load on the walls of long and short tunnels for subsonic compressible and transonic flows. The experimental investigation is carried out only for length parameters to study short and long tunnels. Further, flow visualization is also provided after the formation of the sonic boom. The results of this investigation can be an essential data source for optimum design of high-speed tunnels so as to suppress or break the sound barriers, thus, resulting in a safer high-speed train network.

\section{Introduction}

Many countries have switched over to underground tunnel network construction in order to counter the issue of ever-rising traffic on the road, railways, and air, but the design and safety of high-speed train tunnels remain a daunting challenge. At present, the operating speed of trains is above Mach 0.3, giving rise to the compressibility effect. As the train enters a high-speed tunnel, it gives rise to highly transient air velocity and pressure fluid inside the tunnel from the time of its entry until well after its departure [1]. Moreover, much research has gone into designing trains running through tunnels to meet the need to travel at high velocity, but tunnels remain an obstacle for these trains [2]. Early researchers have studied train and tunnel systems from an aerodynamic and

\footnotetext{
* Corresponding author.

E-mail address: shiblibhai@gmail.com

* Corresponding author.

E-mail address: aeparvathy@usm.my
}

https://doi.org/10.37934/arfmts.88.2.5063 
structural point of view. Still, their main focus was providing comfort zone to passenger, but very few have discussed the problem of sound barrier inside tunnels. Therefore, it becomes almost imperative to understand the sound barriers, the biggest hindrance for the high-speed train.

Furthermore, the complex flow phenomenon of trains entering the tunnel known as the piston effect is a challenge. This investigation highlights the varying strength of compression waves on the walls of the tunnel at different speeds. Thus, pressure load at different locations of the tunnel wall has been discussed for short and long tunnels. The complex flow pattern inside the tunnel tends to be different for long tunnels, short tunnels, open-air, and confined spaces.

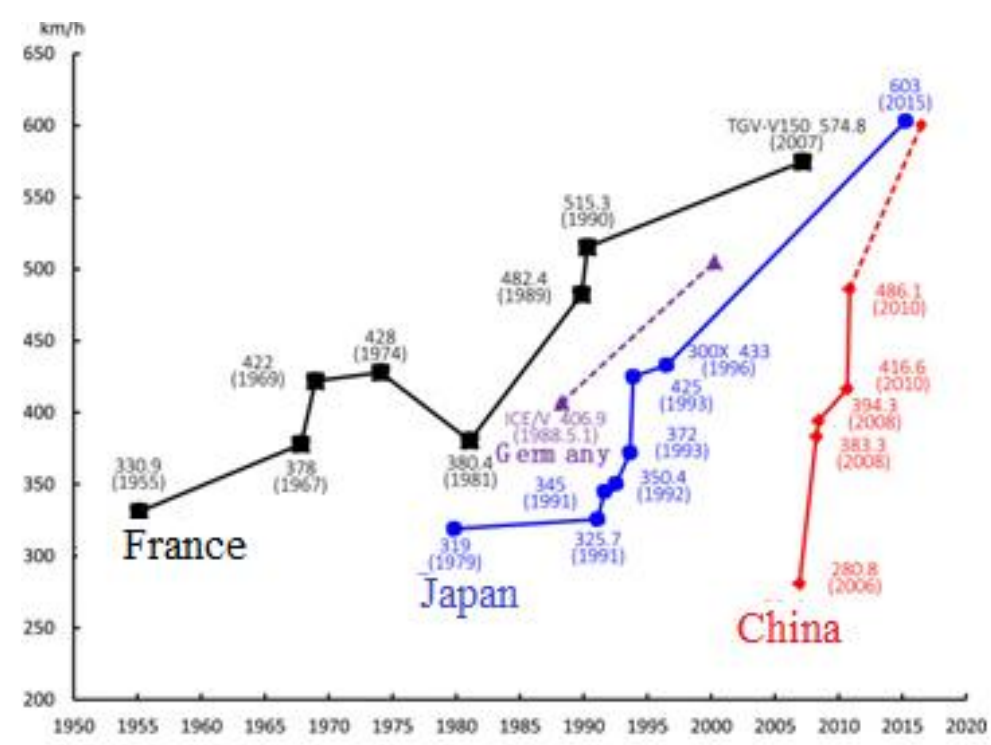

Fig. 1. Development for high-speed trains [2]

A tunnel is an underground, enclosed passage through the surrounding soil/earth/rock/water and opens at both entrance and exit. The minimum length of the tunnel is more than twice the diameter. Underground tunnelling is a futuristic concept where different places interconnect to create a network. Tunnels of different shapes and sizes have been studied by many researchers, such as square, circular, semi-circular, rectangular tunnels, etc., to reduce the pressure loads. The aerodynamic effect of high-speed trains in tunnels was studied [1], but his main focus was on the oscillatory pressure wave pattern. An exhaustive study on the train derailment, damage, and cracking of tunnels at high speeds was done by [3], and he also investigated the effects of derailment. The performance of high-speed trains was investigated by [4], where they concluded that as the train speed increases, the pressure amplitude inside and outside the vehicle increases. He also concluded that the dynamic pressure coefficient increases with an increase in tunnel length. So, it means that the geometric parameters play a vital role. When a high-speed train enters a tunnel, the effect of aerodynamics plays a significant role in the design of tunnels and trains [5]. But this investigation was limited to subsonic flows. Aerodynamic effects of different nose lengths on two trains intersecting in a tunnel at $350 \mathrm{~km} / \mathrm{h}$ were analyzed by [6]. He concluded that the nose length significantly affects the initial compression wave near the tunnel portal. The train passing through the tunnel makes the overall pressure gradient vary from entry to exit [7]. The transient pressure and micro-pressure distribution problems induced by a train passing through the tunnel were investigated [8]. He concluded that the micro pressure waves increased sharply with an increase in train speed. The dip in maximum pressure values for all the tunnel cross-sections decreases longitudinally from the entrance to the exit. The relief duct system was somewhat discussed by [9], but it was limited to subsonic flows. 


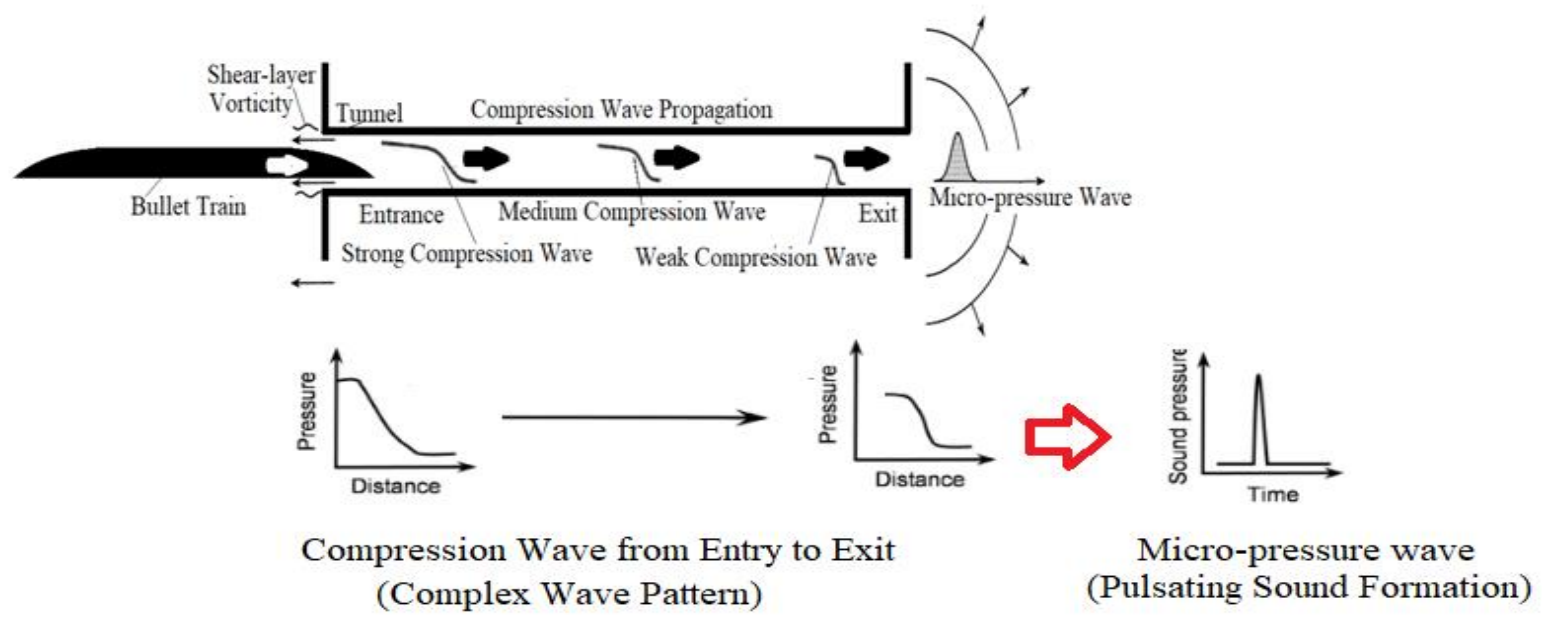

Fig. 2. Piston Effect in High-speed Tunnels

The analytical and experimental study of the compression wave structure generated by a highspeed train entering a tunnel was investigated by [10]. Its strength depends on the portal geometry, blockage, and train speed, as shown in Figure 2. Numerical analysis inside the tunnel was investigated [11], but the kinematic and dynamic behavior of flow inside tunnels remains far from being understood and is limited to the short range of experimental values [12]. Sonic boom leading to aural discomfort outside the tunnel and potentially unstable vehicle and tunnel conditions owing to aerodynamic resistance were investigated [13]. The problems encountered while making a tunnel have mechanical, civil, and even geological dimensions to them. As people set out to bore a tunnel using massive tunnel boring machines (TBM), geological experts come for surveys to identify the kind of rock. Whether the rock is hard, soft, or unstable, to examine if there is a high-pressure water zone or sand inside the mountain. The boring machines work only on hard rock, and for other kinds of rock, the old technique of dynamite explosion is followed. Since it is blind drilling, the global positioning system (GPS) is required to know the exact latitude, longitude, and altitude for the sake of accuracy. Another threat is the billions of tonnes of rock extracted during drilling and boring, which needs to be thrown away. The disposal of excavated rock takes months, if not years. The difficulties do not stop here. Apart from this problem, fire hazards inside the tunnel are common accidents due to collision between trains or derailing or ignition of flammable material. The mount Blanc tunnel 1999 and the Gotthard tunnel 2001, known to be one of the world's safest tunnels, met with catastrophe [14]. Thus, enormous literature can be found regarding the study of high-speed tunnels from an aerodynamic, structural, and safety point of view. Still, the sound barrier as the biggest hindrance in tunnels for the futuristic trains was not discussed. This research explores pressure waves development caused by trains inside the tunnels and geometric parameters influencing the pressure loads on the tunnel walls. So, this paper addresses the fluid flow problem inside the tunnel, which should be considered during the design phase and raises conceptual awareness and safety concerns. The flow just above sound speed and the dynamic variation of wall pressure inside the tunnel have been visualized from entry to exit in order to study the development and behavior of the flow. The previous studies by various authors [15-20] used the microjets to control the base drag in the sudden expansion region and passive techniques used to control base pressure [21-28]. Thus, at high-speeds with the increase in friction, the base pressure increases contrary to the case in low-speed internal combustion engines [29]. 


\section{Experimental Setup}

The pressure is measured stream-wise from entry to exit to discover the correlation between the train speed and the tunnel wall pressure for various geometric lengths and cross-sectional areas. Our purpose is to examine the flow development inside high-speed tunnels to pave way for understanding and suppressing the sound barriers. The current experimental arrangement comprises of high-speed jet apparatus, storage tank, compressor, nozzle, high-speed tunnel models, and pressure sensors attached to DAQ. Pressure readings using DAQ and LabVIEW are logged.

\subsection{Internal Flow Apparatus}

From the internal flow apparatus, the air with a high-compression ratio is passed through a converging square nozzle of dimensions $100 \mathrm{~mm}^{2}$ and into the high-speed tunnel of cross-section $576 \mathrm{~mm}^{2}$ as shown in Figure 3. Equilibrium is attained inside the settling chamber with high stagnation pressure. The flow chart in Figure 4 describes the overall schematic. The convergent nozzle can attain maximum of sonic speed. It will have some disturbance and losses at the nozzle exit when the flow enters the tunnel due to the recirculation zone [30]. Still, the overall trend and visualization are not being affected.

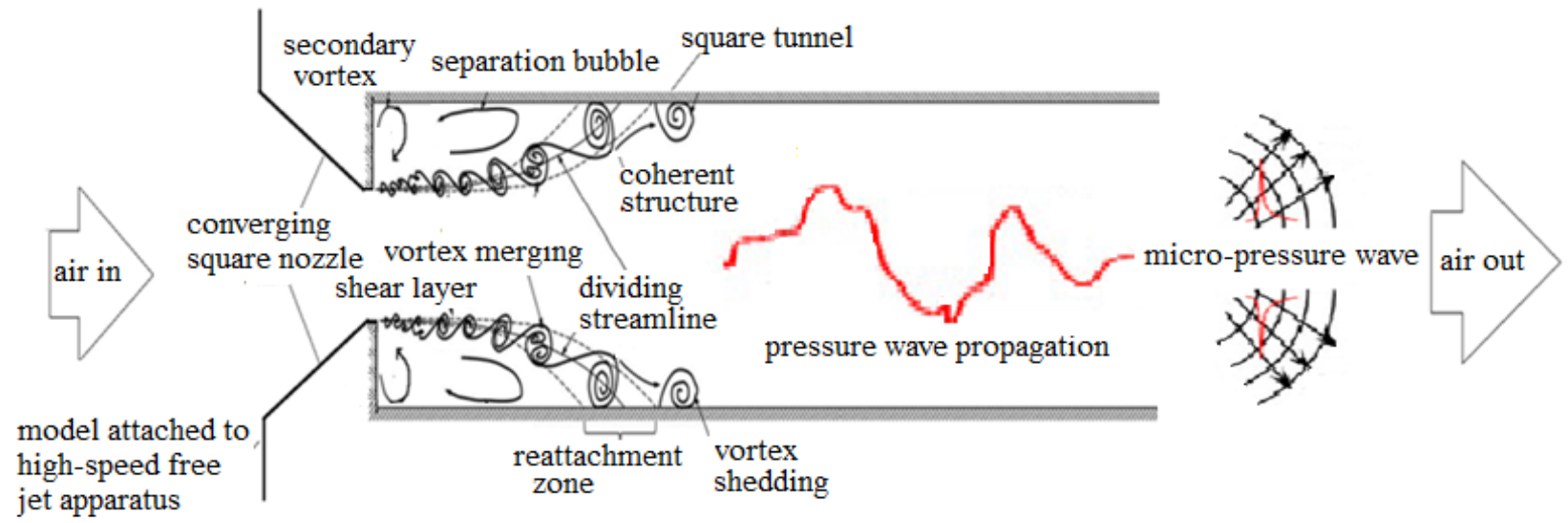

Fig. 3. Experimental Arrangement

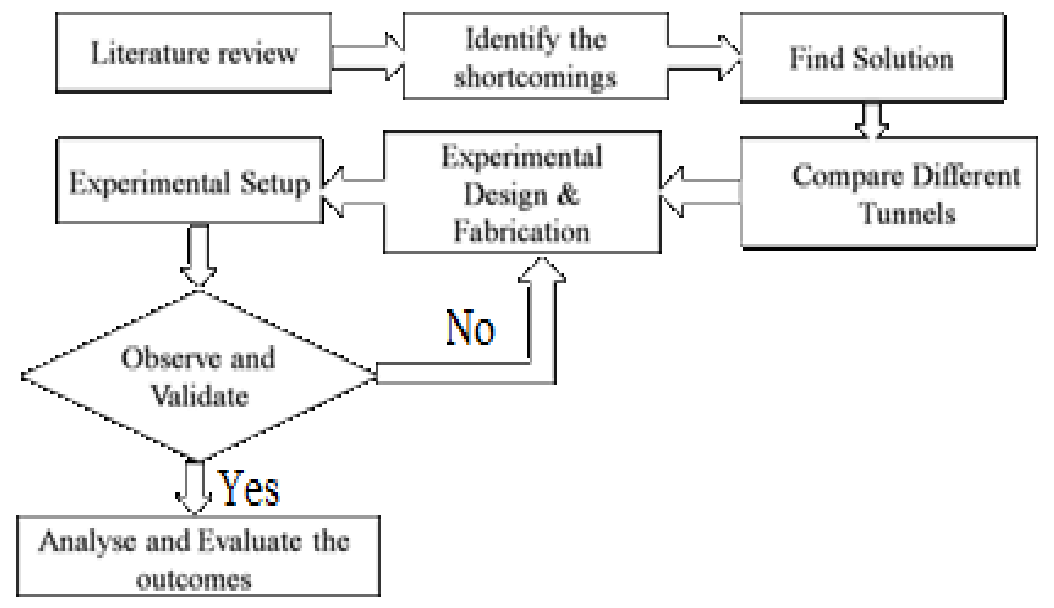

Fig. 4. Methodology 
By changing the NPR, the Mach numbers are varied from $M=0.3$ to 1.02 for fixed-length highspeed short and long tunnels as $96 \mathrm{~mm}$ and $192 \mathrm{~mm}$, respectively. The pressure transducer measures the pressure at the tunnel walls using sixteen channels. Its pressure range is approximately 0-150 psi, and its frequency is 250 samples per second. Lab VIEW acts as an interface between DAQ, sensors, and computers to measure pressure and shadowgraph to visualize the flow field development through side glasses of a high-speed tunnel.

\subsection{Fabrication of Long and Short Tunnel Models}

In the present study, the ratio of the tunnel to the nozzle is 5.76. The subsonic convergent nozzle and high-speed tunnel were analytically studied as shown in Figure 5 and thereafter fabricated from brass as shown in Figure 6. On both sides of the tunnel, a sliding glass was installed for flow visualization. The analytical approach employed for designing phase before fabrication plays an important role. The basic idea is to provide sharp corners leading to initial expansion with reduced non-simple region to minimize fabrication problems. The method of characteristics is employed to design a nozzle just above sonic flow. This program can be used for the preliminary design of any 2$D$ and 3-D nozzle just above sonic flow. These characteristic lines form a grid. The intersection of characteristics (Mach waves) of two original known points having supersonic regime properties in the flow field determine the flow properties of the third point.

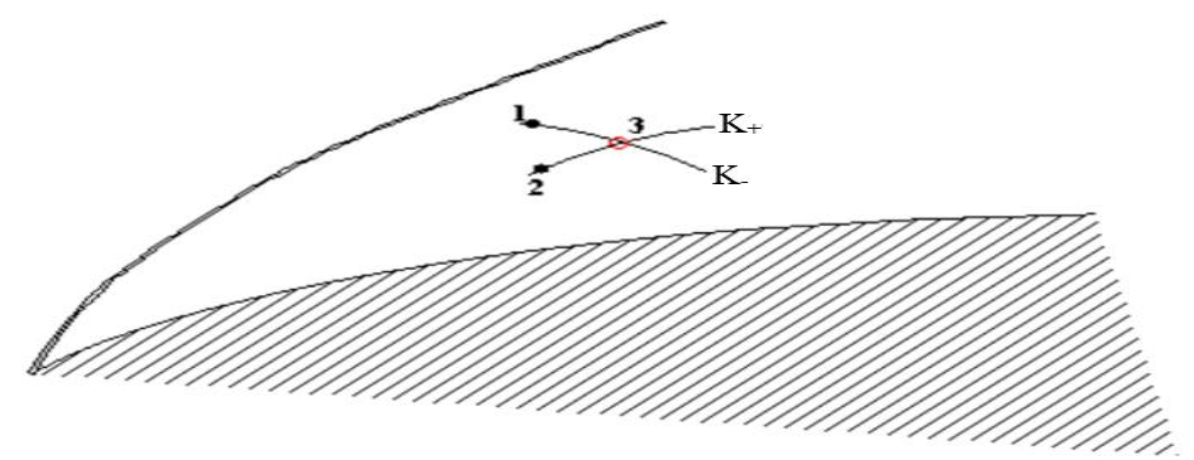

Fig. 5. Schematic Representation for Intersection of the Characteristics Curve

Condition known at points $(1,2)$

Point $\{3\}$ is at the intersection of $\left(\mathrm{K}_{+}, \mathrm{K}_{-}\right)$characteristics

From Adaramola [31],

Point $\{2\} \rightarrow\{\mathrm{M}, \theta\}$ Known $\rightarrow v(M)=\sqrt{\frac{\gamma+1}{\gamma-1}} \tan ^{-1}\left\{\sqrt{\frac{\gamma-1}{\gamma+1}\left(M^{2}-1\right)}\right\}-\tan ^{-1} \sqrt{M^{2}-1}$

$\theta+v(M)=$ const $=K_{-}$

Point $\{2\} \rightarrow\{\mathrm{M}, \theta\}$ Known $\rightarrow \theta_{2}+v\left(M_{2}\right)=$ const $=K_{-}$

Mach and flow direction solved for point 3

Point $\{3\} \rightarrow\left[\begin{array}{c}\theta_{1}+v_{1}=\theta_{3}+v_{3} \\ \theta_{2}+v_{2}=\theta_{3}-v_{3}\end{array}\right] \rightarrow$ 
$M=$ Solve $\left[v_{3}=\sqrt{\frac{\gamma+1}{\gamma-1}} \tan ^{-1}\left\{\sqrt{\frac{\gamma-1}{\gamma+1}\left(M^{2}-1\right)}\right\}-\tan ^{-1} \sqrt{M^{2}-1}\right]$

$\theta_{2}+v\left(M_{2}\right)=$ const $=K_{-}$

Further points will be followed by the iterative solution. Get a new angle and repeat iteration and solve/compute for each point of the contour. Strategic contour will "absorb" Mach waves in the divergent section should have isentropic flow.

$$
\begin{aligned}
& v(1.0)=\sqrt{\frac{\gamma+1}{\gamma-1}} \tan ^{-1}\left\{\sqrt{\frac{\gamma-1}{\gamma+1}\left(1.0^{2}-1\right)}\right\}-\tan ^{-1} \sqrt{1.0^{2}-1}=0 \\
& \theta_{w \text { Max }}=v\left(M_{a}\right)-0 \rightarrow \theta_{w \text { Max }}=v\left(M_{a}\right) \\
& \theta_{w \text { Max }}+v_{a}=\left(K_{-}\right)_{c}=v_{\text {exit }} \\
& 2 \theta_{w \text { Max }}=\left(K_{-}\right)_{c}=v_{\text {exit }} \\
& \theta_{w \text { Max }}=\frac{v_{\text {exit }}}{2}
\end{aligned}
$$

This is the criterion for minimum nozzle length and the length of give expansion angle is more important the precise shape of the nozzle. Design of Minimum Length Nozzle for an exit Mach number of 1.026 using the method of characteristics

$$
\begin{aligned}
& M_{\text {exit }}=1.026 \rightarrow v\left(M_{\text {exit }}\right)=\sqrt{\frac{\gamma+1}{\gamma-1}} \tan ^{-1}\left\{\sqrt{\frac{\gamma-1}{\gamma+1}\left(1.026^{2}-1\right)}\right\}-\tan ^{-1} \sqrt{1.026^{2}-1} \\
& v\left(M_{\text {exit }}\right)=0.38^{\circ} \\
& \theta_{w \text { Max }}=\frac{v_{\text {exit }}}{2}=0.19^{\circ}
\end{aligned}
$$

The pressure was measured from the top. All the cases studied are without a train for high-speed tunnel investigation. Only the effect of speed leading to pressure load on tunnel walls and the sonic boom at the exit of the tunnel has been observed using DAQ and shadowgraph to avoid problems of sound barrier in futuristic trains and tunnels. Pressures are measured for the short and long tunnels at different tab positions using DAQ. 


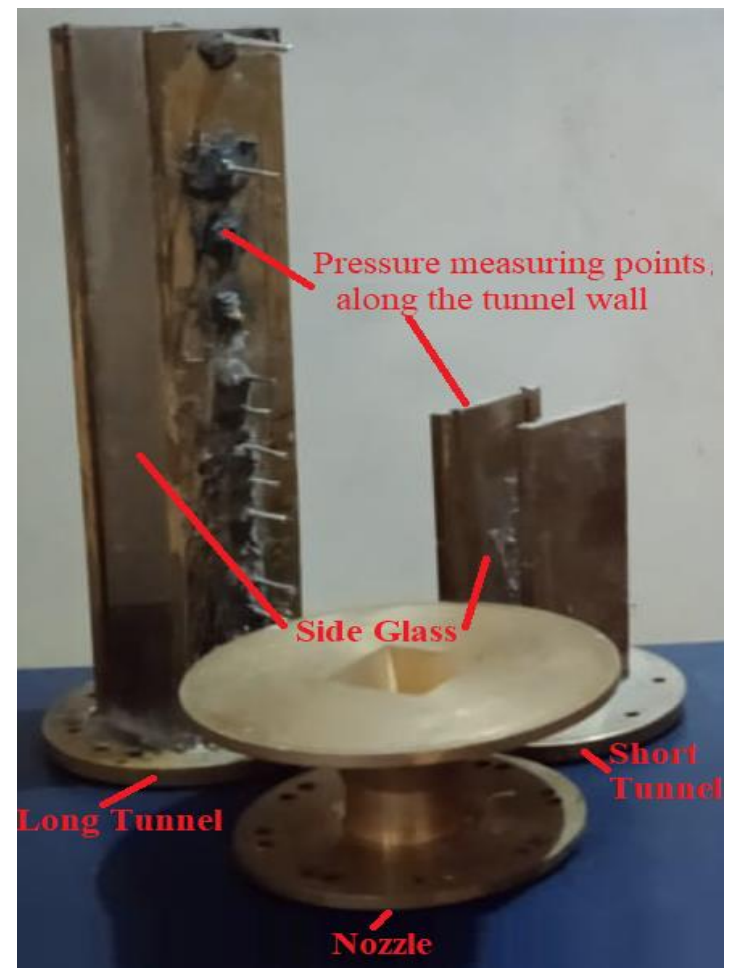

Fig. 6. Square Nozzle, Short and Long Tunnels

A helium spark arc in conjunction with a $150 \mathrm{~mm}$ concave mirror was employed in a shadowgraph system to capture the flow pattern. The parallel beam from the mirror was made to pass through the jet flow field and was projected on the screen. The CCD camera was used to take photographs of shadowgraph as there is a gradient in a density tending light rays to converge or diverge. The result with diamond shocks shows that the flow has a little bit exceeded Mach 1 and is under-expanded, as shown in Figures 7 to 12.

\section{Results}

Pressure load in a tunnel demonstrates fluctuation as train enters and exits it. The high positive pressure occurs when a train enters the entrance portal. Still, a sudden reduction in this high pressure as the train moves through the tunnel leads to a complicated fluctuating propagation of pressure waves from entry to exit. Also, the pressure field in the tunnel becomes oscillatory and is known as the "Ejector Pump" phenomenon [32].

\subsection{Short High-speed Tunnel}

The flow field characteristics in the tunnel become oscillatory by shedding vortex downstream from the nozzle into the tunnel. The unwanted oscillations may lead to some losses, but the overall structure for mainstream flow remains the same and can be seen in the tunnel wall pressure from Figures 7 to 12 . The present investigation considers the parameters such as the area ratio (5.76) between tunnel and nozzle exit, L/W ratio of the tunnel as 8 and 4 respectively for the long and short tunnel. The exit Mach number is of the maximum value of 1.02 . 

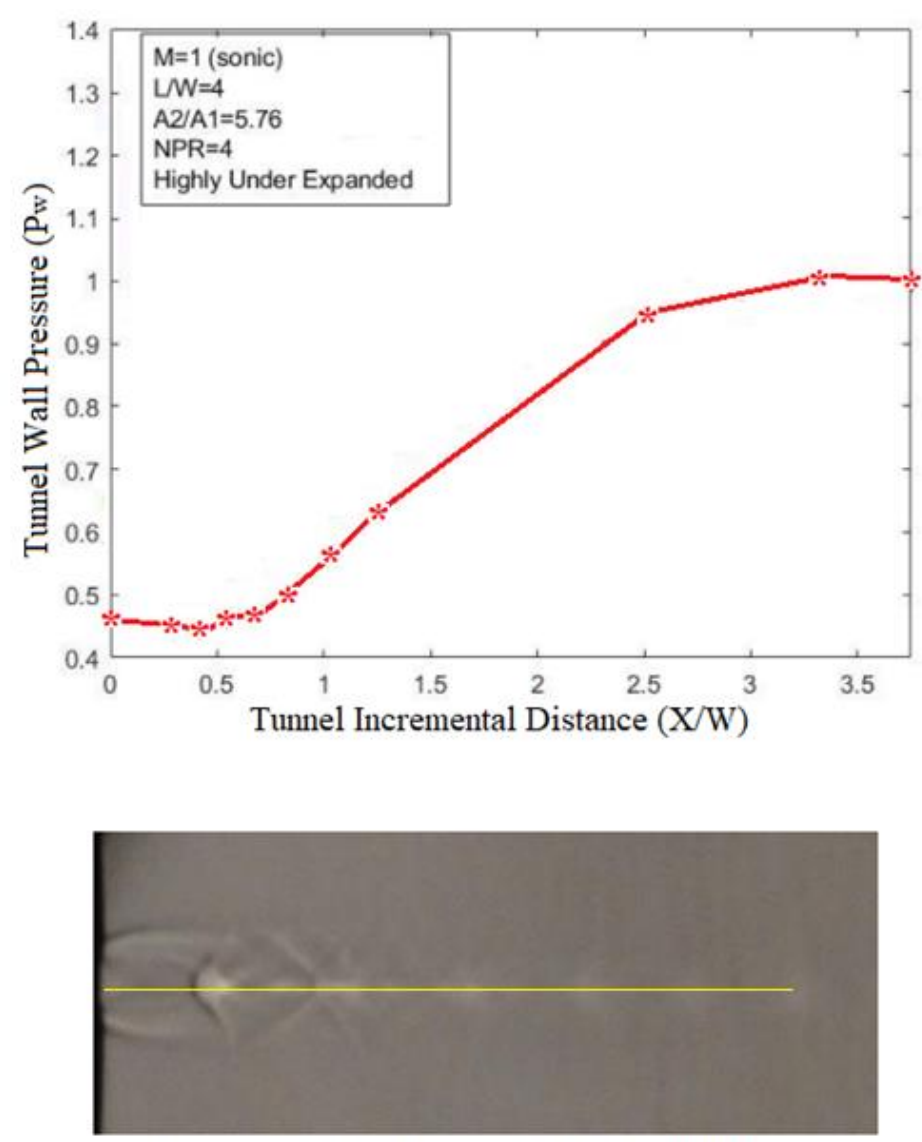

Compression and Expansion inside Tunnel

Fig. 7. Development of Flow at Highly Under-Expanded Sonic Regime

The level of expansion was exploited between NPR 1.6 to 3 to achieve required Mach numbers less than or equal to or just above 1 . The subsonic regime takes place when the fluid velocity is less than the acoustic speed. The flow Mach number is called sonic flow when it is $M=1$. In this section, we focus our attention on wall pressure-flow development in the tunnel. The tunnel wall pressure $\left(P_{w}\right)$ indicates the flow development along its wall and flow visualization, as shown in Figure 7 and Figure 8. The trend of the graph shows the strong impact of the increasing wall pressure from entry to exit. Experiments were carried out for perfectly expanded and under-expanded cases to assess the effect of expansion level. Also, wall pressure distribution without a train for short and long tunnels shows the influence of flow and geometric parameters such as Mach number, area ratio, and lengthto-width ratio. For $\mathrm{L} / \mathrm{W}=4$, the shock diamonds were observed with less sharpness for highly underexpanded flows than a long tunnel. It can be seen along the yellow line showing shock diamonds in Figure 7, indicating compression and expansion wave inside the tunnel. Further, when the NPR was reduced to moderately under-expanded flow, the intensity also reduces, as shown in Figure 8 . The shadowgraph shows for design Mach number as an optimum expanded flow inside the tunnel, and its value is 1.89 for the subsonic /sonic regime at $M<=1$, as shown in Figure 9. 


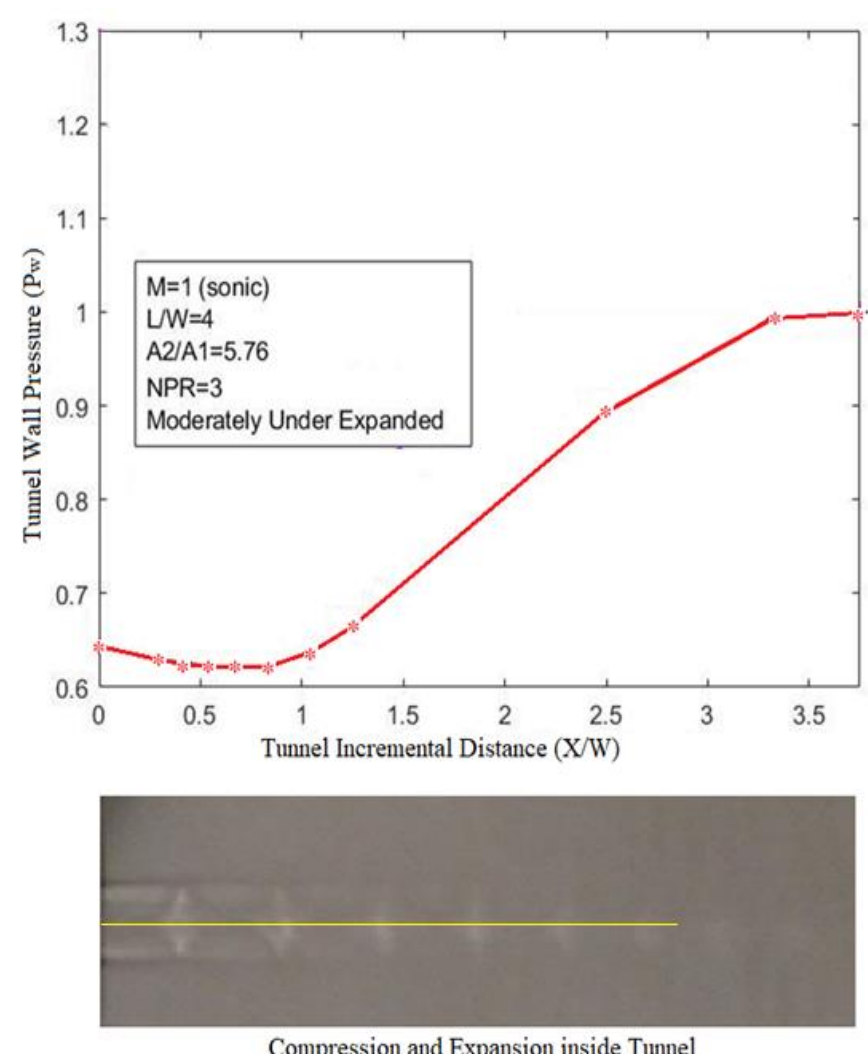

Fig. 8. Development of Flow at Moderately UnderExpanded Sonic Regime
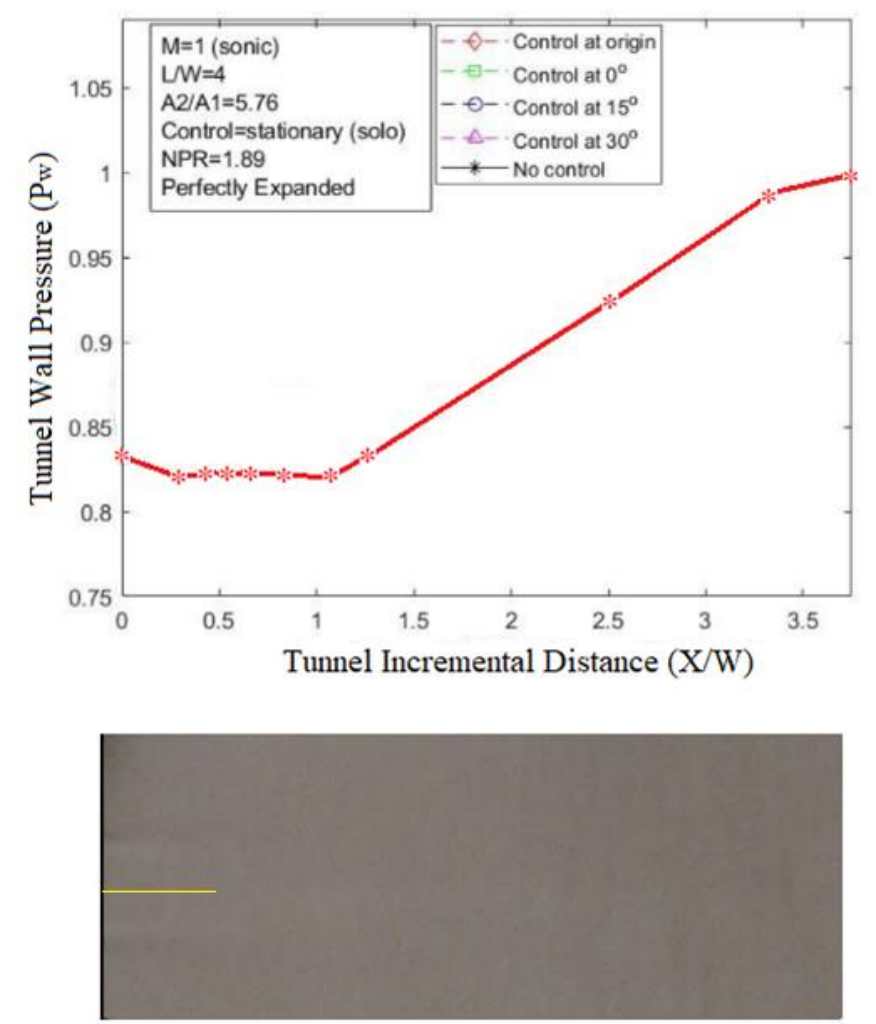

Shock Diamonds Disappeared inside Tunnel

Fig. 9. Development of Flow at Perfectly Expanded Sonic Regime 


\subsection{Long High-speed Tunnel}

After expansion from the nozzle to the tunnel, the complicated flow field becomes vibrant, as shown by the tunnel pressure from entry to exit. Also, there is a sudden increase in the pressure gradient in the tunnel from the train's entry until the train nose leaves the tunnel. The air upstream at the frontal portion of the train in the tunnel moves along the train, but after a critical point in the tunnel, air flows backward, and an abrupt change in pressure is observed. Ahead of the train, lower velocities and higher pressures are measured in the long tunnel, but the flow parameters change on reversal of flow. A pressure drop suddenly occurs when the train nose passes and the train's tail enters the tunnel.
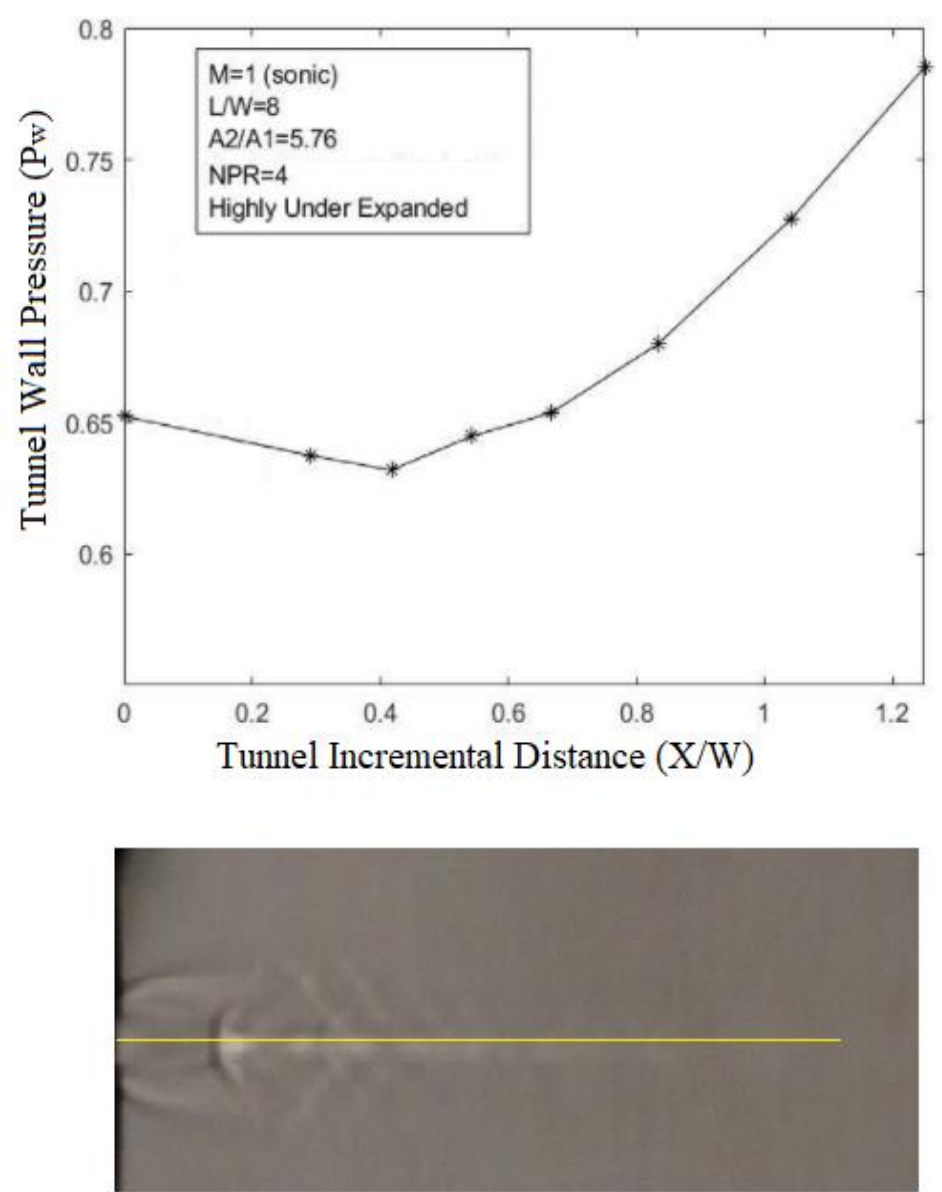

Compression and Expansion inside Tunnel

Fig. 10. Development of Flow at Highly Under-Expanded Case for $\mathrm{M}=1$

The research on flow along the wall shows that the pressure on the tunnel walls is greatly affected by the square tunnel's length and width. For $L / W=8$, shock diamonds were observed with sharpness for highly under-expanded flows. It can be seen along the yellow line in Figure 10, indicating firm compression and expansion wave inside the tunnel. Further, when the NPR was reduced to moderately under-expanded flow, the intensity also reduces, as shown in Figure 11 . The shadowgraph shows for design Mach number as an optimum expanded flow inside the tunnel is 1.89 for the subsonic/sonic regime at $M<=1$. Wall pressure results for long tunnel length $\mathrm{L} / \mathrm{W}=8$ are shown in Figure 12. From the results, it is evident that there are some oscillations in the tunnel flow field. It may be due to the small tunnel length and due to the influence of the backpressure. 

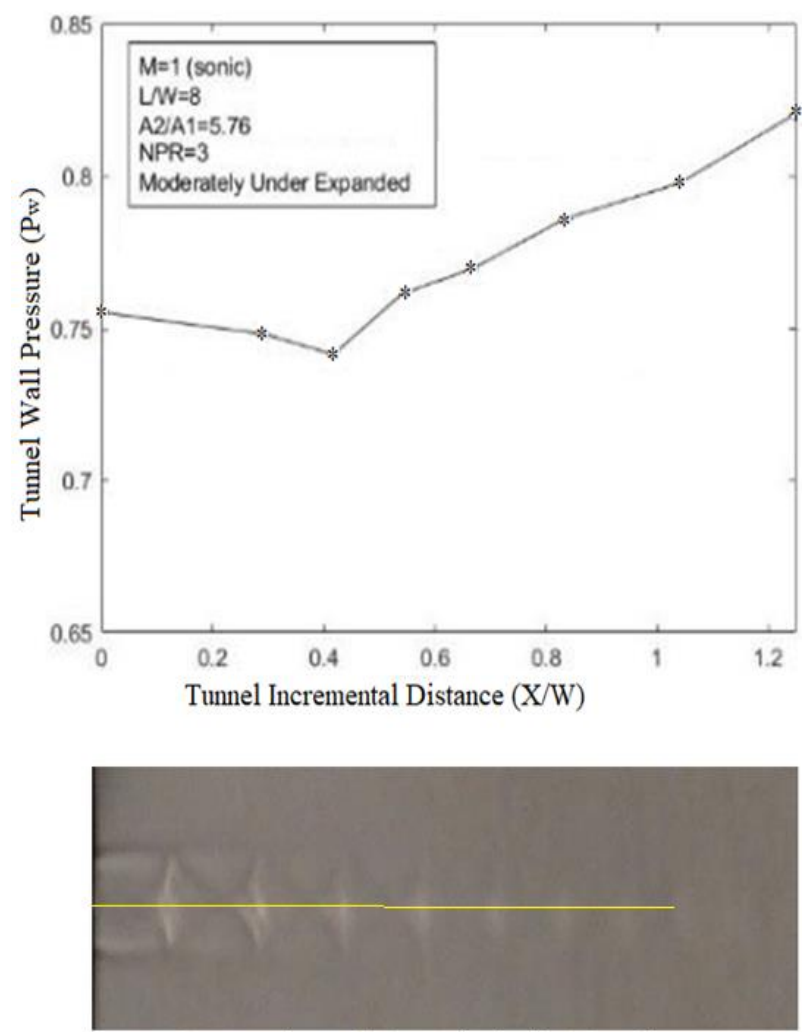

Compression and Expansion inside Tunnel

Fig. 11. Development of Flow at Moderately Under-Expanded Case for $\mathrm{M}=1$

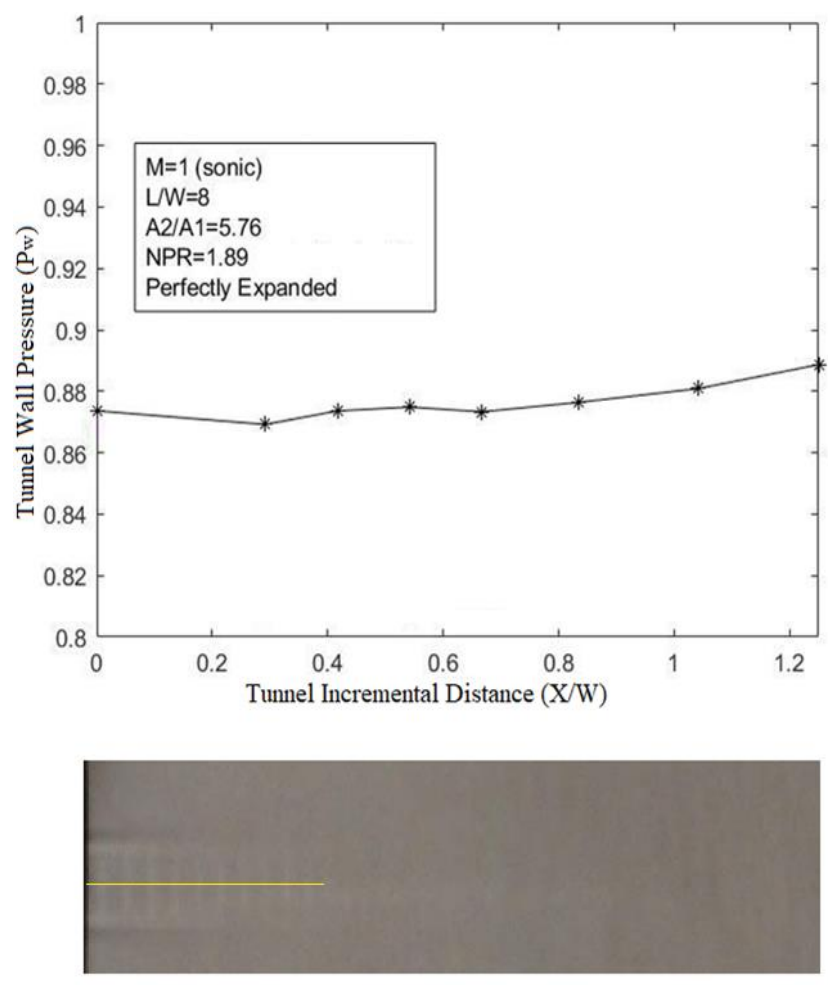

Shock Diamands Disappeared inside Tunnel

Fig. 12. Development of Flow at Perfectly Expanded Case for $\mathrm{M}=1$ 


\section{Conclusions}

The compressible flow problem is tested for the short and long tunnels. The experimentally investigated tunnel models and the flow visualization of flow development inside tunnels show different flow patterns and different intensities of shock diamonds in both tunnels. The importance of suppressing sound barriers inside high-speed tunnels without compromising on speed by the cause-effect method in the complex flow development inside the tunnel can help us understand the flow and to control the complex flow inside the tunnel. Thus, we can have more compatible and safer high-speed trains and tunnels. The curvature of the frontal nose or rear tail leads to different crosssections lengthwise between the train and the tunnel. The minimum cross-section acts as a highspeed sonic or just a tiny supersonic nozzle leading to the formation of a shock wave with huge vibration and noise. Further, the length-to-width (L/W) ratio for a high-speed tunnel affects the static pressure without adversely affecting the pressure gradient. The study on tunnel wall pressure shows that the pressure is affected by the aspect ratio, expansion ratio, and Mach number. However, optimum length and width for tunnels can be for only a particular speed and vary with the expansion and Mach number level. Control of a complex flow field to bring about a demanded shift is of great industrial significance, but it needs more flow development inside tunnels. This technological development lowers drag for bullet trains under land and sea and saves fuel consumption, thus facilitating the low-cost green industrial process. This study shows the development of smaller aerodynamic forces at the entrance and the exit of a tunnel at high Mach numbers nearing sonic speed. This study represents flow development analysis of short and long tunnels. It can be beneficial to suppress these irregular forces leading to optimum design intent and a safer underground tunnelling network.

\section{Acknowledgment}

This research was funded by Kementerian Pendidikan Malaysia, Grant No.203/PAERO/6071437, and the APC was funded by Universiti Sains Malaysia and Kementerian Pendidikan Malaysia. The authors wish to acknowledge and thank the Indian Institute of Technology, Kanpur, India, for allowing us to utilize research facility in the supersonic laboratory.

\section{References}

[1] Gilbert, Timothy. "Aerodynamic effects of high-speed trains in confined spaces." PhD diss., University of Birmingham, 2014.

[2] Niu, Jiqiang, Yang Sui, Qiujun Yu, Xiaoling Cao, and Yanping Yuan. "Aerodynamics of railway train/tunnel system: A review of recent research." Energy and Built Environment 1, no. $4 \quad$ (2020): 351-375. https://doi.org/10.1016/i.enbenv.2020.03.003

[3] Yan, Qixiang, Minghui Sun, Songyong Qing, Zhixin Deng, and Weijie Dong. "Numerical investigation on the damage and cracking characteristics of the shield tunnel caused by derailed high-speed train." Engineering Failure Analysis 108 (2020): 104-205. https://doi.org/10.1016/i.engfailanal.2019.104205

[4] Liu, Tanghong, Zhenhua Jiang, Xiaodong Chen, Jie Zhang, and Xifeng Liang. "Wave effects in a realistic tunnel induced by the passage of high-speed trains." Tunneling and Underground Space Technology 86 (2019): $224-235$. https://doi.org/10.1016/i.tust.2019.01.023

[5] Miao, Xiujuan, Kan He, Guglielmo Minelli, Jie Zhang, Guangjun Gao, Hongliang Wei, Maosheng He, and Sinisa Krajnovic. "Aerodynamic Performance of a High-Speed Train Passing through Three Standard Tunnel Junctions under Crosswinds." Applied Sciences 10, no. 11 (2020): 3664. https://doi.org/10.3390/app10113664

[6] Chen, Xiao-Dong, Tang-Hong Liu, Xi-Sai Zhou, Wen-hui Li, Tai-Zhong Xie, and Zheng-Wei Chen. "Analysis of the aerodynamic effects of different nose lengths on two trains intersecting in a tunnel at $350 \mathrm{~km} / \mathrm{h}$." Tunnelling and Underground Space Technology 66 (2017): 77-90. https://doi.org/10.1016/j.tust.2017.04.004

[7] Fairbairn, A. G. "Tunnel ventilation, including aerodynamics." In Proceedings of the Institution of Civil EngineersCivil Engineering108, no. 6, (1995):32-41. https://doi.org/10.1680/icien.1995.28047 
[8] Zhang, Lei, Ming-zhi Yang, Ji-qiangNiu, Xi-feng Liang, and Jian Zhang. "Moving model tests on transient pressure and micro-pressure wave distribution induced by train passing through tunnel." Journal of Wind Engineering and Industrial Aerodynamics 191 (2019): 1-21. https://doi.org/10.1016/i.jweia.2019.05.006

[9] Reinke, P., and A. Busslinger. "Improvement of aero and thermodynamics of rail tunnels by cross-connections with shut-off devices." (2011): 38-43.

[10] Howe, M. S., M. lida, T. Fukuda, and T. Maeda. "Theoretical and experimental investigation of the compression wave generated by a train entering a tunnel with a flared portal." Journal of Fluid Mechanics 425 (2000): $111-132$. https://doi.org/10.1017/S0022112000002093

[11] Funatsu, T., T. Hoshino, H. Sawae, and N. Shimizu. "Numerical analysis to better understand the mechanism of the effects of ground supports and reinforcements on the stability of tunnels using the distinct element method." Tunnelling and Underground Space Technology 23, no. 5 (2008): 561-573. https://doi.org/10.1016/i.tust.2007.10.003

[12] Ahmad, Nor Elyana, Essam Abo-Serie, and Adrian Gaylard. "Mesh optimization for ground vehicle aerodynamics." CFD Letters 2, no. 1 (2010): 54-65.

[13] Li, Wenhui, Tanghong Liu, Xiaoshuai Huo, Zhengwei Chen, Zijian Guo, and Li Li. "Influence of the enlarged portal length on pressure waves in railway tunnels with cross-section expansion." Journal of Wind Engineering and Industrial Aerodynamics 190 (2019): 10-22. https://doi.org/10.1016/j.jweia.2019.03.031

[14] Vuilleumier, F., A. Weatherill, and B. Crausaz. "Safety aspects of railway and road tunnel: example of the Lötschberg railway tunnel and Mont-Blanc road tunnel." Tunnelling and Underground Space Technology 17, no. 2 (2002): 153158. https://doi.org/10.1016/S0886-7798(02)00018-4

[15] Khan, Sher Afghan, Abdul Aabid, and C. Ahamed Saleel. "Influence of micro jets on the flow development in the enlarged duct at supersonic Mach number." International Journal of Mechanical and Mechatronics Engineering 19, no. 01 (2019): 70-82.

[16] Pathan K.A., Dabeer P.S., and Khan S.A. "An investigation of effect of control jets location and blowing pressure ratio to control base pressure in suddenly expanded flows." Journal of Thermal Engineering6, no. 2 (2020): 15-23. https://doi.org/10.18186/thermal.726106

[17] Khan A., Aabid A., and Khan S.A. "CFD analysis of convergent-divergent nozzle flow and base pressure controlusing micro-JETS." International Journal of Engineering and Technology 7, no. 3.29 (2018): $232-235$. https://doi.org/10.14419/ijet.v7i3.29.18802Published

[18] Fharukh Ahmed G.M., Ullah M.A., and Khan S.A. "Experimental study of suddenly expanded flow from correctly expandednozzles." ARPN Journal of Engineering and Applied Sciences 11, no. 16 (2016): 10041-10047.

[19] Pathan K.A., Dabeer P.S., and Khan S.A. "Effect of nozzle pressure ratio and control jets location to control base pressure in suddenly expanded flows." Journal of Applied Fluid Mechanics 12, no. 4 (2019): 1127-1135. https://doi.org/10.29252/jafm.13.02.30049

[20] Baig M.A.A., Al-Mufadi F., Khan S.A., and Rathakrishnan E. "Control of base flows with micro jets." International Journal of Turbo and Jet Engines 28, no. 1 (2011): 59-69. https://doi.org/10.1515/tij.2011.009

[21] Pathan, Khizar Ahmed, Syed Ashfaq, Prakash S. Dabeer, and Sher Afgan Khan. "Analysis of parameters affecting thrust and base pressure in suddenly expanded flow from nozzle." Journal of Advanced Research in Fluid Mechanics and Thermal Sciences 64, no. 1 (2019): 1-18.

[22] Pathan, Khizar Ahmed, Prakash S. Dabeer, and Sher Afghan Khan. "Influence of expansion level on base pressure and reattachment length." CFD Letters 11, no. 5 (2019): 22-36.

[23] Khan, Sher Afghan, Mohammed Asadullah, and Jafar Sadhiq. "Passive control of base drag employing dimple in subsonic suddenly expanded flow." Int. J. Mech. Mechatron. Eng. IJMME-IJENS 18, no. 03 (2018): 69-74.

[24] Pathan K.A., Dabeer P.S., and Khan S.A. "An investigation to control base pressure in suddenly expanded flows." International Review of Aerospace Engineering 11, no. $4 \quad$ (2018): $162-169$. https://doi.org/10.15866/irease.v11i4.14675

[25] Pathan, Khizar Ahmed, Prakash S. Dabeer, and Sher Afghan Khan. "Investigation of base pressure variations in internal and external suddenly expanded flows using CFD analysis." CFD Letters 11, no. 4 (2019): 32-40.

[26] Aabid, Abdul, Ambreen Khan, Nurul Musfirah Mazlan, Mohd Azmi Ismail, Mohammad Nishat Akhtar, and Sher Afghan Khan. "Numerical simulation of suddenly expanded flow at Mach 2.2." International Journal of Engineering and Advanced Technology 8, no. 3 (2019): 457-462.

[27] Sajali, Muhammad Fahmi Mohd, Abdul Aabid, Sher Afghan Khan, Fharukh Ahmed Ghasi Mehaboobali, and Erwin Sulaeman. " Numerical Investigation of Flow Field of a Non-Circular Cylinder." CFD Letters 11, no. 5 (2019): 37-49.

[28] Pathan K.A., Dabeer P.S., and Khan S.A. "Enlarge duct length optimization for suddenly expanded flows." Advances in Aircraft and Spacecraft Science 7, no. 3 (2020): 203-214. https://doi.org/10.12989/aas.2020.7.3.203 
[29] Otkur, Murat. "Altitude Performance and Fuel Consumption Modelling of Aircraft Piston Engine Rotax 912 S/ULS." Journal of Advanced Research in Applied Sciences and Engineering Technology 23, no. 1 (2021): 18-25. https://doi.org/10.37934/araset.23.1.1825

[30] Asadullah, Mohammed, Sher Afghan Khan, Waqar Asrar, and E. Sulaeman. "Low-cost base drag reduction technique." Int. J. Mech. Eng. Robot. Res 7, no. 4 (2018): 428-432. https://doi.org/10.18178/ijmerr.7.4.428-432

[31] Adaramola, M. S., O. G. Akinlade, D. Sumner, D. J. Bergstrom, and A. J. Schenstead. "Turbulent wake of a finite circular cylinder of small aspect ratio." Journal of Fluids and Structures 22, no. 6-7 (2006): 919-928. https://doi.org/10.1016/i.jfluidstructs.2006.04.007

[32] Greitzer, Edward M., Choon Sooi Tan, and Martin B. Graf. Internal flow: concepts and applications. Vol. 3. Cambridge University Press, 2007. 